\title{
REVISTAS INDEXADAS Y OTROS VICIOS ACADÉMICOS
}

\author{
Sergio Villalobos \\ Premio Nacional de Historia, 1992
}

\section{PASIVIDAD DE LOS ACADÉMICOS}

El mundo de los intelectuales y de los universitarios ha sido traspasado por un extraño sistema que distribuye categorías de publicaciones de acuerdo con directivas que provienen de las ciencias naturales y de las llamadas exactas, de acuerdo con sus exigencias en los Estados Unidos y los círculos satélites de otros países. Se trata de un sistema que procura uniformar exigencias adaptándolas al sistema imperante en aquel país y otros, que detentan el dominio en el pensamiento y procuran manejarlo, ahora en el método, pero que puede ser utilizado, y quizás ya lo sea, para una orientación ideológica. Todo depende de cómo se le emplee.

Puede ser una de las peores formas de "imperialismo" cultural.

Un amigo juicioso y perspicaz me ha señalado que el control sobre el saber puede tener una intención política y que contar con registros del quehacer intelectual puede ser utilizado por organismos oficiales con fines espurios. El pensamiento humano podría ser controlado o por lo menos inducido con cualquier fin. Dentro de ese sistema estarían nuestras universidades, Conicyt y el Ministerio de Educación. La única solución es la plena autonomía universitaria y el manejo de recursos suficientes sin discriminación por especialidades.

El saber y su expresión escrita requieren de plena libertad, sin subterfugios, de modo que el espíritu personal se exprese de la manera más amplia.

Es probable que en el dominio de las ciencias naturales los aportes de los investigadores puedan ser normados de manera que calcen perfectamente en los temas específicos y sea perceptible el aporte innovador. Así, por ejemplo, 
puede haber un estudio sobre "La vacuna antipertrusis diftérica en dos dosis. Cuarenta casos típicos" o también sobre "El efecto de la conjunción de Júpiter y Venus en las mareas de sicigia”. En tales casos, los fenómenos son perfectamente acotados, no admiten interpretaciones ni especulaciones; por lo tanto, pueden señalarse reglas para su exposición.

No sucede lo mismo en el campo de las humanidades, donde las disciplinas encierran una fuerte ductibilidad y dependen, en definitiva, de la intranquilidad del estudioso, sus percepciones, su interpretación y, en suma, de su personalidad intelectual, sin descartar posiciones filosóficas e ideológicas. Así ocurre en las letras, la filosofía, la historia, la antropología y en cuantas disciplinas giran en torno al hombre como creador de cultura y de ámbitos sociales.

A nadie se le ha ocurrido señalar pautas para comprender la belleza y el mensaje que encierran los versos del Mío Cid o las coplas de Jorge Manrique. Al contrario, cuanta mayor autonomía revelen los estudiosos de esas obras, mayor será la riqueza de sus aportes. Del mismo modo, para un estudioso histórico de la sociedad rural en el valle de Curacaví, no se puede prescribir un método, ni el uso de tales y cuales fuentes, series estadísticas o el apego a tales o cuales conceptos generales de un sociólogo de Provenza o California.

El secreto está en que la historia se refiere a hechos singulares, que ocurrieron en determinada época o momento y no se repiten jamás y que, además, son altamente discutibles. Habrá tantos enfoques y visiones como historiadores se dediquen al tema.

Estas realidades, que han ido envolviendo de manera más ceñida a nuestros intelectuales de las humanidades, no han suscitado ninguna resistencia ni protesta, como si un conformismo les hubiese adormecido. Al parecer, se encuentran derrotados o, lo que es peor, se han adaptado a recibir beneficios económicos y de prestigio dispensados desde las revistas indexadas, que en los centros de estudio favorecen carreras ligeras.

\section{EL NEGOCIO INTELECTUAL}

Los académicos, igual que todos los seres humanos, viven preocupados de su situación, el ascenso y el prestigio, que al fin se reflejan en la posición ocupada en alguna universidad, un centro de estudios o un cargo público. En esa competencia darwiniana puede haber buenos y malos métodos. Entre estos últimos están las publicaciones en revistas "indexadas". 
El origen del sistema fue muy curioso. Un negociante de libros de Chicago, para facilitar las adquisiciones por parte de las universidades, inventó un sistema de información de contenidos de las revistas científicas y tuvo éxito. Aumentaron las ventas. En los misterios de los centros universitarios el sistema se transformó y pasó a ser un medio para calificar los aportes de las revistas, aparentemente mejoraba la eficacia; pero de ahí al negocio había un paso.

Ocurre, también, que quienes publican en las indexadas reciben pagos nada despreciables, en un derrame del lucro o venta del alma a Mefistófeles. Y como los humanistas están mal pagados, al final un coro de ángeles los salvará.

Por arte de magia se ha extendido la idea de que las mencionadas revistas gozan de gran prestigio. Publicar en ellas otorga prestancia, realza al organismo que las edita, facilita escalar posiciones, ganar concursos de todo tipo y aumentar las relaciones internacionales. El negocio prospera, las universidades fomentan el negocio, porque significa alcanzar una imagen provechosa. En la propaganda se menciona la cantidad anual de artículos en las "indexadas" que han publicado sus académicos y de esa manera se cree aumentar el prestigio. Conicyt, por su parte ha concedido gran categoría a los artículos de marras y en sus calificaciones se llegó a darles tanta o mayor importancia que a los libros publicados, en un disparate intelectual de marca mayor. Las universidades, a su vez, siguieron ese criterio y en la calificación de sus académicos, o de los candidatos para serlo, señalaron altos grados a los artículos indexados.

En las cotizaciones del mercado todo ello ha creado una "burbuja" económica e inflación de prestigio: las universidades señalan orgullosas su aporte a la "indexación", impresionan a los apoderados y a los estudiantes, al staff superior de la propia universidad y las otras, al Ministerio de Educación y al Consejo de Rectores y a la opinión pública. Difícil que haya una inversión más rentable. Nadie ha reparado en que es una forma de lucro.

En esas condiciones, un pobre investigador que ha empleado tantos años trabajando en un libro, no puede competir con un mozalbete que en 20 ó 25 páginas "indexadas" exhibe su escuálida formación llena de expresiones esotéricas y citas de autores altisonantes.

La inversión no puede ser más provechosa. 


\section{LA NEGACIÓN DEL HOMBRE}

Se supone que el académico que investiga es por naturaleza un ser libre y que la comunidad intelectual debe respetar su condición. Actualmente, sin embargo, se colocan toda clase de trabas para normar su creatividad, encajonarla y mantenerla a gusto de la burocracia universitaria. Un artículo no debe pasar de tantas páginas, exigencia formal que no considera para nada el espacio que puede requerir cabalmente una investigación. Lo importante es mezquinar el espacio para dar cabida a numerosos artículos, aunque sean de menor trascendencia.

En cada número de una revista debe haber cierta cantidad de colaboraciones de gente de otras universidades, ojalá extranjeras. Al parecer se trata de un espíritu universalista, que debe imponerse aunque haya que desplazar a investigaciones propias de gran peso.

La aplicación del anterior criterio puede relegar a segundo término trabajos sobre nuestra realidad, para acoger temas que escasamente pueden interpretarnos. Así habrá que dar importancia a asuntos que poco o nada nos interesen, como pueden ser las disputas entre unos vecinos de Coahuila, el cuidado del ganado en la provincia de Entre Ríos o los comienzos del cultivo de la caña azucarera en Barbados.

Cierto es que en ese tipo de colaboraciones pueden haber sugerencias metodológicas, pero lo mismo puede ocurrir en los temas propios que son desplazados.

Otra originalidad es que no se pueden incluir ensayos, porque son la negación de la "ciencia", es decir, el pensamiento exclusivamente interpretativo no es valioso, hay que atenerse a la descripción lisa y llana, cercana al positivismo. El vuelo de las ideas es indeseable.

Si pensamos que el objeto final de la historia es la reflexión sobre el hombre y ello se efectúa fundamentalmente a través de los ensayos, la función de las revistas en cuestión es negativa.

Las limitaciones parecen ir más lejos aún. En España el Anuario de Estudios Americanos ha llegado a objetar las formas de redacción, imponiendo un estilo o falta de estilo en un simplismo desértico. A un autor chileno se le objetó el empleo de una metáfora porque la exposición debía ser lisa y llana para no caer en la literatura. Los intelectuales que han propiciado esa modalidad, ayunos de cultura real, no comprenden que entre el pensamiento y su expresión escrita hay una íntima conexión, que lejos de estar reñida con la belleza, se ilumina con ella (metáfora repudiable), haciendo que el 
mensaje sea más penetrante y más convincente, y permita expresar mejor lo que deseamos transmitir. Es la magia de la palabra, que ignoran los palurdos.

Es probable que los autómatas españoles y quizás también los que andan por nuestra tierra, no comprendan que el lenguaje está íntimamente unido al vuelo del pensamiento y que éste, a la vez, expresa la intuición, una categoría del espíritu difícil de definir, pero que indudablemente pasa más allá de los hechos concretos y claramente demostrables, para adivinar, crear y sugerir en la finura del espíritu.

Imaginamos que para los “indexados” hispánicos, los nombres de Spengler, Huizinga, Braudel y Toynbee, son imágenes horrorosas.

La España misma presenta buenos nombres que funden el idioma con la sabiduría: Azorín, Unamuno, Ortega y Gasset, etc.

Para manejarse en todas estas cosas, es necesario ser humanista, comprender al hombre.

\section{ART NOUVEAU Y ART DECO}

Corrían las primeras décadas del siglo XX, cuando grupos de arquitectos, movidos por el deseo de ser originales, promovieron las tendencias mencionadas. Querían superar los viejos estilos y otros que estaban en boga, que complacían a los grupos dominantes y la sociedad respetaba con beneplácito.

La necesidad de ser originales les llevaba a romper con lo conocido, forzando ideas de cualquier tipo, acudiendo a recursos llamativos que rompiesen la solidez esencial de las construcciones. Había que llenar espacios, curvar las líneas, crear recovecos y ángulos insospechados de manera que todo pareciese muy moderno. Por último, si no se destruía la esencia sólida de la construcción, distraer con detalles decorativos, insospechados y curiosos, aunque fuesen postizos. Así se lograba parecer modernos.

El mismo fenómeno ocurre en la historia de hoy.

Han aparecido generaciones que, incapaces de adentrarse en las realidades económicas, sociales, culturales y políticas, porque están muy sólidamente establecidas y es difícil enmendarlas, han recurrido a aspectos superficiales, llamativos y ornamentales, que dan apariencia de novedad y atraen la atención hacia sus autores.

Ahí están la historia de las mentalidades y representaciones, la de la vida corriente, el funcionamiento de las redes sociales, la "historia desde abajo", 
el ocio y las costumbres populares y otros temas que, sin ser enteramente inútiles, son antes que nada elementos decorativos que se agregan al edificio sólido de la historia.

La construcción esencial y duradera sigue estando en el concreto armado, las vigas resistentes, la base firme, el cálculo aplicado y materiales reunidos con paciencia y sin prisa. El adorno de yeso, las figuritas pintorescas y los coloridos, no forman parte de la estructura fundamental.

En la historia debería ocurrir lo mismo que en la arquitectura, donde la tendencia llamada Bauhaus barrió con los primores ornamentales e impuso las líneas rectas, los planos despejados, los espacios claros, los grandes ventanales y el predominio de lo esencial.

\section{PRODUCCIÓN DE INTELECTUALES}

El negocio de las universidades y de los círculos intelectuales se ha beneficiado ampliamente con la veta de los postgrados, los diplomados, premios diversos y otros artilugios. Todo ello sirve en la propaganda, los folletos, la prensa y la televisión, con el efecto llamativo sobre los estudiantes, los apoderados y la opinión pública. También en el Ministerio de Educación, Conicyt y otras reparticiones.

Se aligeran o reducen los años destinados a los títulos profesionales, la elaboración de tesis y otras exigencias, y de ese modo los egresados son impulsados a los magísters y los doctorados, que ofrecen un porvenir brillante y que por el momento con las matrículas engrosan las rentas de las universidades. El lucro sigue adelante.

Es impresionante ver cómo las casas de estudio exhiben triunfalmente las cifras de doctores que militan en sus aulas y la cantidad de doctores que se titulan.

Hasta la década de 1950, los doctores, excepto los de la medicina, eran rara avis, y las universidades funcionaban perfectamente. Sus profesores eran de categoría, cumplían perfectamente con los más altos niveles del saber y desarrollaban excelentes investigaciones.

Nuestro país gozaba de un alto prestigio cultural, sus universidades eran reconocidas por su calidad en el extranjero y ejercían gran influencia en los países hermanos. 
El país sobrevivía sin doctores. Andrés Bello no tuvo ningún título ni grado, Barros Arana tampoco, ni Ricardo Latcham ni Guillermo Feliu Cruz. Este último ni siquiera terminó la educación media.

Muchos otros de los grandes historiadores solo tuvieron un título profesional y si todos se destacaron fue porque en la esencia de las cosas, lo que realmente cuenta es la inteligencia, la voluntad y el esfuerzo personal.

Lo que llevo dicho se refiere fundamentalmente a las humanidades y quizás no deba aplicarse a las ciencias naturales y exactas, donde la capacitación requiere de formación especial y debe contar con laboratorios, equipos y relaciones con los centros del extranjero.

Reduciéndonos al campo de la historia, la sobreproducción de magíster y doctores sin ser enteramente criticable, ha conducido a nuevos problemas.

El primero es de carácter ocupacional. No hay suficientes fuentes de trabajo y es lamentable observar que quienes estudiaron con entusiasmo e ilusiones, deambulan desorientados. Algunos logran un puesto en tal o cual colegio o liceo o se emplean en cargos públicos. Otros desean incorporarse al sistema universitario y forman una fuerza de presión; pero solamente los que se alinean en la corriente ideológica de tal o cual universidad logran cumplir con sus esperanzas.

Una consecuencia adicional, aunque no menos importante, es la cantidad de monografías que circulan en el mercado, provenientes de tesis y trabajos menores, cuyos autores presionan por la publicación, siendo muchas veces acogidos por las revistas "indexadas". Esa tendencia no es mala en sí, pero produce vicios que pueden ser criticados.

Los investigadores jóvenes y otros que no lo son tanto creen ser parte de corrientes innovadoras y aspiran a un papel preponderante, sin comprender sus deficiencias epistemológicas, fallas de método, de lógica y de criterio, que no captan porque es el sesgo imperante en su medio.

Pruebas al canto. Es frecuente asentar tesis generales en que la influencia de la sociología, vertientes filosóficas e ideológicas conforman la base de sustentación. De ese modo se desprecian las obras anteriores y se las acusa de tales o cuales elementos obsoletos o negativos, sin atender a la conformación íntegra de esas investigaciones y aun a aspectos que contradicen la acusación. Personalmente me correspondió hace poco tiempo comentar en una revista histórica un trabajo de orden etnohistórico, con tales fallas de lógica y criterio, que lo hacía incoherente, encerrando una absoluta contradicción en sí mismo. 
Los noveles estudiosos de la historia buscan en grandes teorizantes el apoyo para sus ideas, de manera de parecer originales y profundamente innovadores. No obstante, muchos de esos teorizantes ya han sido superados y al fin lo que realmente cuenta es la propia investigación y la solidez que le dan sus conclusiones bien fundamentadas.

Ha sido frecuente citar a Foucault, Anderson u Hobsbawm, especie de lazarillos diligentes que guían ante la propia falta de visión ¿Cuándo se comprenderá que el propio juicio, proveniente de las fuentes históricas, es lo que prevalece? Hay que atreverse a ser realmente originales.

\section{PROCEDIMIENTOS INQUISITORIALES}

A raíz del Concilio de Trento, la Iglesia Católica estableció el Index, un registro en que caían las obras consideradas heréticas y que ningún creyente debía leer. Ahora, el índice moderno de las ciencias naturales y exactas, impuesto desde el extranjero, determina, en sentido contrario, las obras que deben ser leídas.

Para implantar el régimen se han estatuido reglas que en caso de ser contravenidas pueden acabar con los propios inquisidores.

Es obligación recurrir a los informes de dos o tres especialistas, ajenos al organismo editor, que supuestamente son personas serias, de peso y que dominan la materia sometida a su consideración. El problema comienza con la elección: ¿quiénes son los idóneos, con buenos antecedentes, imparciales y bien intencionados?

El editor puede caer en grandes vacilaciones y en fallas evidentes. Puede que elija a personas no del todo competentes, también a quienes profesan métodos extraños o pecan de modernismo en el manejo de aparatos electrónicos. También pueden ser personajes unidos a "redes intelectuales" e ideológicas contrarias al artículo que debe ser informado. Por último, el comentarista puede ser enemigo del autor sometido a su consideración o simplemente contrario a su pensamiento.

Los procedimientos inquisitoriales quedan resguardados por el secreto y el anonimato, de modo que los informantes son irresponsables, en el término jurídico.

Frente a todos estos aspectos debemos preguntarnos qué hace de una revista que sea importante en su ramo y que contribuya realmente al avance de la cultura. Recuerdo que en una ocasión el historiador Mario Góngora 
opinó que la calidad de una revista dependía de la categoría de sus artículos y de sus colaboradores.

Durante un largo período de tiempo, los Anales de la Universidad de Chile y la revista Mapocho han sido las publicaciones culturales de mayor prestigio en el país, sin necesidad de procedimientos esotéricos. Simplemente cuenta la honradez intelectual.

Algunas revistas que gozaron de un bien ganado prestigio, como Historia de la Universidad Católica y Atenea de la Universidad de Concepción, han caído en la megalomanía de la indexación. Otras se aprestan a dar el salto.

Al concluir estas páginas debo hacer un reconocimiento especial a Cuadernos de Historia de la Universidad de Chile, que pese a las reglas de la indexación, se ha manejado de manera juiciosa y acertada.

Debe entender que este artículo es un grito a favor de la libertad. 